\title{
Anti-Hemophilia Factor Unit
}

National Cancer Institute

\section{Source}

National Cancer Institute. Anti-Hemophilia Factor Unit. NCI Thesaurus. Code C69077.

One international unit of antihemophilic activity is equivalent to the quantity of

antihemophilic factor (Factor VIII) present in $1 \mathrm{~mL}$ of normal human plasma. 